\title{
Effects of Ketoprofen in Spermatogenesis of Mice Exposed to Continuos Hypobaric Hypoxia
}

\author{
Efecto del Ketoprofeno en la Espermatogénesis de \\ Ratones Expuestos a Hipoxia Hipobárica Continua
}

\author{
Ricardo Hartley ${ }^{1}$; Daniel Conei ${ }^{2,3,4}$; Leandro Torres ${ }^{5}$ \& Mariana Rojas ${ }^{3}$
}

HARTLEY, R.; CONEI, D.; TORRES, L.; \& ROJAS, M. Effects of ketoprofen in spermatogenesis of mice exposed to continuos hypobaric hypoxia. Int. J. Morphol., 37(4):1572-1577, 2019.

SUMMARY: Hypoxia hypobaric $(\mathrm{HH})$ can cause alterations at testicular level, with temperature increase, intrascrotal alteration and deterioration of spermatogenesis. Nonsteroidal anti-inflammatory drugs (NSAIDs) such as ketoprofen have anti-angiogenic properties, and can decrease testicular abnormalities. The objective of the study was to evaluate the effect of ketoprofen on spermatogenesis of mice exposed to continuous hypobaric hypoxia. 78 Mus musculus CF-1 male mice 3 to 4 months old were used and subjected to HH in chamber at $4200 \mathrm{~m}$. They were divided into 13 groups $(\mathrm{G})$ of 6 animals: 10 with HH cycles $(1,2,3,4$ and 8 , lasting 8.3 days each cycle, two groups each) and 3 in normoxia (Nx). Intraperitoneal ketoprofen $25 \mathrm{mg} / \mathrm{kg}$ was administered every 4 days. Euthanasia of these animals was performed at the end of each cycle and in the case the Nx groups at the end of cycles 1, 4 and 8 . Percentage of microhematocrit and reticulocytes were measured in blood smears and a morphometric and histopathological analysis of the height of the epithelium, the tubular diameter and the diameter of the tubular lumen was made. It was shown that hematocrit increases continuously up to 8 cycles, while reticulocytes increase up to 3 cycles. Continuous $\mathrm{HH}$ decreases the tubular diameter in a sustained manner and proportional to $\mathrm{HH}$ cycles, and the height increased only in the groups subjected to 8 cycles. The groups treated with ketoprofen saw a decrease in angiogenesis, presenting some degree of protection at the testicular level.

KEY WORDS: Ketoprofen; Continuous hypobaric hypoxia; Testicular abnormalities; Angiogenesis.

\section{INTRODUCTION}

Among the studied physiological systems that are altered in hypoxia hypobaric $(\mathrm{HH})$ is the reproductive system. Numerous studies in $\mathrm{HH}$ attributed to a decrease in normal reproduction parameters, which can result in infertility (Farias et al., 2005; Zepeda et al. 2014; Yao et al., 2016; Farias et al., 2018). However, adaptation mechanisms are described to $\mathrm{HH}$ favoring the flow of oxygen to the different organs, such as increased respiratory rate, increased cardiac output and release of erythropoietin, among others (Hralová et al., 2013). In man, and specifically testicular level, alterations should be generated, among others, mechanisms of adaptation to $\mathrm{HH}$ as angiogenesis in the testicular parenchyma, which causes an increase in temperature intraescrotal altering and impairing the process spermatogenesis (Viscor et al., 2018). Hypoxia in various systems has been described as a factor of cellular stress, generating an increase in the production of reactive oxygen species in cell metabolism, species classically linked to a decline in sperm quality and development of spermatogenesis (Cikutovic et al., 2009).

The atmospheric pressure at sea level which is 760 $\mathrm{mm} \mathrm{Hg}$ as you ascend to a higher altitude level, decreases, as the partial pressure of the components $(\mathrm{O} 2, \mathrm{~N} 2, \mathrm{CO} 2)$. Oxygen is the $21 \%$ of the components of the atmosphere. The atmospheric pressure at 1000 meters is $674 \mathrm{~mm} \mathrm{Hg}$, and the 4200 meters is $428 \mathrm{~mm} \mathrm{Hg}$. The partial pressure of oxygen also drops significantly and therefore, the partial

\footnotetext{
${ }^{1}$ Instituto de Investigación e Innovación en Salud, Universidad Central de Chile, Santiago, Chile.

${ }^{2}$ Programa de Doctorado en Ciencias Morfológicas, Facultad de Medicina, Universidad de La Frontera, Temuco, Chile.

${ }^{3}$ Laboratorio de Embriología Comparada, Programa de Anatomía y Biología del Desarrollo, Instituto de Ciencias Biomédicas, Facultad de Medicina, Universidad de Chile, Santiago, Chile.

${ }^{4}$ Departamento de Ciencias de la Salud, Universidad de Aysén, Coyhaique, Chile.

${ }^{5}$ Instituto de Ciencias Naturales, Universidad de Las Américas, Santiago, Chile.
} 
pressure in the alveolar air, the saturation of the blood hemoglobin, the oxygen content and transport, so that the supply to the tissue may be compromised (Fouillot \& Barrault, 1982).

Hypoxia was produced by the increase at high altitudes because the least amount of oxygen molecules per liter of air and the resultant decrease in oxygen pressure, which is caused by an increased difficulty for the alveoli to scavenge oxygen necessary for carrying out the various metabolic activities of the body (Irarrázaval et al., 2017). The literature indicates that hypoxia affects male reproductive function by decreasing the fertile capacity in man (Okumura et al., 2003) and causes alterations in reproductive parameters in mammals (Zepeda et al.). Hypoxia exerts an inhibitory effect on cell populations in division. Therefore, it is possible to relate changes in the germline HH provided (Kim \& Han, 1969).

Faced with downdling oxygen present in these environments, various adaptive responses of the organism, such as neoangiogenesis and vasodilation, in order to increase blood flow to different tissues, thereby compensating for the decreased oxygen are triggered. This response induces testicular damage and affects spermatogenesis due to increased temperature intrascrotal (Farias et al., 2005), as a result of increased blood flow. Whereas nonsteroidal antiinflammatory drugs (NSAIDs) have anti-angiogenic properties, may be administered in mice subjected to hypoxia, reduced testicular alterations.

The objective of the present work is to evaluate the protective effect that would have ketoprofen on mouse spermatogenesis exposed to continuous hypobaric hypoxia.

\section{MATERIAL \& METHOD}

Experimental design. In this study, 78 mice (Mus musculus) male CF-1 strain healthy and sexually mature (3-4 months old) which were obtained from the animal facilities of the Faculty of Medicine, University of Chile were used. They were kept under a light/dark 12-12 h, at room temperature and fed with commercial pellets and water ad libitum, under conditions identical to those of bioregion of origin. Was studied alterations in reproductive parameters in testis of mice exposed to simulated $\mathrm{HH}$ in hypobaric chamber at 4200 m. 9 groups of 6 animals continued to $\mathrm{HH}$ for 1, 2, 3, 4, 6 , and 8 cycles of the seminiferous epithelium (duration of one cycle 8.3 days) were subjected to the camera. Ketoprofen was administered intraperitoneally $0.1 \mathrm{~mL} 1 \%$ (Dosage: 25 $\mathrm{mg} / \mathrm{kg}$ ) every 4 days to 6 of these groups and the other three groups were used as control ketoprofen. Euthanasia of these animals was performed at the end of each cycle and in the case of control at the end of cycle 1, 4 and 8. Six groups remained outside the hypobaric chamber, and control hypoxia, age and ketoprofen, 3 of ketoprofen these were administered every 4 days and euthanasia of these animals was performed at the end of the first, fourth and last cycle. Ketoprofen was used $1 \%$ injection (Naxpet ${ }^{\circledR}$, Drag Fharma). The administration of ketoprofen $1 \%$ remained until the time of euthanasia for each selected group, was every 4 days from the start of the experiment, the intraperitoneal administration of ketoprofen was the $25 \mathrm{mg}$ / $\mathrm{kg}$ dose of ketoprofen $(1 \mathrm{mg} / 0.1 \mathrm{~mL})$. The group number is the number of elapsed cycles of the seminiferous epithelium in normoxia $(\mathrm{Nx})$, hypobaric hypoxia Control ( $\mathrm{HH} \mathrm{C}$ ) and ketoprofen hypobaric hypoxia $(\mathrm{HH} \mathrm{K}),(\mathrm{G} 1=8.3$ days, 1 cycle; $\mathrm{G} 2=16,6$ days, 2 cycles; $\mathrm{G} 3=24.9$ days, 3 cycles; $\mathrm{G} 4=33.2$ days, 4 cycles, first complete spermatogenesis, and G8 $=66.4$ days, 8 cycles, Second full spermatogenesis).

Hematological parameters. The first day of the experiment all mice were weighed, then euthanized when weighed again. Euthanasia was performed with ketamine, at which time each mouse underwent a cardiac puncture to withdraw a sample of blood into a heparinized syringe and stored in eppendorf tubes $(3 \mathrm{~mL})$ to determine hematologic response by percent microhematocrit and percentage of reticulocytes in blood smears stained with brilliant cresyl blue, readings were made at $100 \mathrm{X}$ microscope by counting 100 cells.

Histological processing. After euthanasia of animals both testicles, which were released from the epididymis and surrounding tissues were removed. Both were fixed in aqueous Bouin. One hour later puncture was performed with $25 \mathrm{G}$ needle both as caudal and cranial pole after $4 \mathrm{~h}$. Testicular cross section for total $24 \mathrm{~h}$ fixation in Bouin was performed, and then be fixed in alcohol $70 \%$ until samples were processed. Having fixed the testicles routine histological techniques and inclusion in paraplast were conducted cross-sectional thickness of $5 \mu \mathrm{m}$ were obtained.

Morphometric and histopathological analysis. Each sample was cuted in semi serial way, in order to examine a total of 10 tubules per mouse for morphometric analysis of epithelium height, tubular diameter and tubular lumen diameter. Each cut was stained with hematoxylin-eosin and microscope observed. All measurements were performed considering at least 60 tubules for each group, being digitally captured and processed with a computer software analysis software Image Tool version 3.0. For morphological analysis, were considered the tubular blockage, presence of epithelial vacuolization and progress of the stages of the tubular epithelium. 
Statistical analysis. All results are expressed as mean \pm standard deviation. Statistical analysis of the results is performed with nonparametric Anova test Kruskal-Wallis test and Dunn's multiple comparison, which allows you to compare and determine whether there are significant differences in the results obtained between the experimental groups in relation to a control group.

\section{RESULTS}

\section{Hematologic variables}

Hematocrit. The average hematocrit (HTO) as evaluated groups are presented in Table I. HTO increased in animals subjected to hypoxia in groups 1 and 2 (8.3 and 16.6 days exposed to hypoxia), with or without ketoprofen, compared to the control group $\mathrm{Nx}$, there is a significant statistical difference was observed $(\mathrm{p}<0.05)$ at $\mathrm{HH} \mathrm{K}$ group compared to the control group $\mathrm{Nx}$. Then reach for the highest percentages of HTO in groups 4 (to 33.2 days) compared to the group $\mathrm{Nx}$ control, significant statistical differences $(\mathrm{P}<0.01)$. G8 also showed significant and very significant differences compared to Nx. No statistically significant difference between groups subjected to hypoxia with and without ketoprofen is observed.

Table I. Effect of hypobaric hypoxia continuous and ketoprofen on hematocrit.

\begin{tabular}{lcc}
\hline Groups & $\begin{array}{c}\text { Hematrocrit }(\%) \\
\text { Mean } \pm \text { S.D. }\end{array}$ & $\begin{array}{c}\text { p value Nx v/s } \\
\text { HH C or HH K }\end{array}$ \\
\hline G1 Nx & $43.05 \pm 7.84$ & - \\
G1 HH C & $48.66 \pm 6.92$ & $>0.05$ \\
G1 HH K & $51.46 \pm 7.37$ & $>0.05$ \\
G2 HH C & $46.48 \pm 4.44$ & $>0.05$ \\
G2 HH K & $52.24 \pm 6.01$ & $<0.05^{*}$ \\
G3 HH C & $41.42 \pm 5.00$ & $>0.05$ \\
G3 HH K & $40.38 \pm 8.63$ & $>0.05$ \\
G4 Nx & $43.15 \pm 3.44$ & - \\
G4 HH C & $61.80 \pm 5.96$ & $<0.01^{* *}$ \\
G4 HH K & $60.28 \pm 6.44$ & $<0.05^{*}$ \\
G8 Nx & $34.56 \pm 1.63$ & - \\
G8 HH C & $48.48 \pm 5.11$ & $<0.05^{*}$ \\
G8 HH K & $50.81 \pm 7.74$ & $<0.01^{* *}$ \\
\hline
\end{tabular}

Reticulocytes. The mean reticulocyte evaluated as group are presented in Table II a marked increase in the percentage of reticulocytes only the first 33.2 days of exposure to hypoxia is observed. G1 HH C presented a significant difference $(\mathrm{p}<0.01)$ and $\mathrm{G} 2 \mathrm{HH} \mathrm{C}$ a significant difference $(\mathrm{p}$ $<0.001$ ) compared to G1 Nx, unlike G1 and G2 HH K do not exhibit significant differences. G3 HH C and K exhibit significant difference $(\mathrm{p}<0.05)$ and highly significant, respectively, compared to G4 Nx. G4 HH C also has very significant difference compared to G4 Nx, unlike G4 HH K having no significant difference. No statistically significant difference between groups subjected to hypoxia with and without ketoprofen is observed. Also is shown the marked increase in the percentage of reticulocytes to 24.9 days of exposure to hypoxia, then lower the percentage, 33.2 days, but remains higher than the $\mathrm{Nx}$ group, finally not differ significantly to 66.4 days of exposure to hypoxia as compared to the $\mathrm{Nx}$ control group of mice of the same age.

Table II. Effect of hypobaric hypoxia continuous and ketoprofen on reticulocytes.

\begin{tabular}{lcc}
\hline Groups & $\begin{array}{c}\text { Reticulocytes }(\%) \\
\text { Mean } \pm \text { S.D. }\end{array}$ & $\begin{array}{c}\text { p value Nx v/s } \\
\text { HH C or HH K }\end{array}$ \\
\hline G1 Nx & $2.50 \pm 1.05$ & - \\
G1 HH C & $9.83 \pm 2.48$ & $<0.01 * *$ \\
G1 HH K & $7.50 \pm 1.64$ & $<0.05^{*}$ \\
G2 HH C & $12.80 \pm 1.58$ & $<0.001 * * *$ \\
G2 HH K & $8.33 \pm 3.27$ & $>0.05$ \\
G3 HH C & $14.80 \pm 0.90$ & $>0.05$ \\
G3 HH K & $17.83 \pm 8.03$ & $>0.05$ \\
G4 Nx & $2.60 \pm 0.55$ & - \\
G4 HH C & $7.83 \pm 2.32$ & $<0.01 * *$ \\
G4 HH K & $5.67 \pm 2.16$ & $<0.05 *$ \\
G8 Nx & $5.60 \pm 1.03$ & - \\
G8 HH C & $5.00 \pm 1.67$ & $<0.05^{*}$ \\
G8 HH K & $4.67 \pm 1.86$ & $<0.01 * *$ \\
\hline
\end{tabular}

\section{Histologic variables}

Tubular diameter. The average tubular diameter as the evaluated groups are presented in Table III. A decrease is observed in the tubular diameter in the groups subjected to hypoxia the first month. Only with significant differences $(\mathrm{p}<0.05)$ compared with $\mathrm{G} 1 \mathrm{HH} \mathrm{K} \mathrm{Nx}$, very significant difference $(\mathrm{p}<0.01) \mathrm{G} 3 \mathrm{HH} \mathrm{C}$ and G4 HH K, and significant G4 HH C and G4 HH K compared with Nx difference. At the end of the second month G8 Nx, presented a decrease in tubular diameter, showing a significant difference with G8 HH K. There is no significant statistical difference between the groups subjected to hypoxia with and without ketoprofen.

Lumen diameter. The average diameter of the tubular lumen as the evaluated groups is presented in Table IV. The diameter of the tubular lumen increased the first 16.6 days of exposure to hypoxia, showing a statistically significant difference $(\mathrm{p}<0.01)$ between G1 Nx and G2 HH C. At 24.9 and 33.2 days the diameter the tubular lumen of the groups subjected to hypoxia is less than G4 Nx control group, showing a significant difference $(\mathrm{p}<0.01)$ between G3 HH C and G4 Nx, and extremely significant difference $(\mathrm{p}<0.001)$ between $\mathrm{G} 4$ HH K and G4 Nx. At 66.4 days, the groups did not show 
Table III. Effect of hypobaric hypoxia continuous and ketoprofen on tubular diameter of seminiferous tubules.

\begin{tabular}{lcc}
\hline Groups & $\begin{array}{c}\text { Tubular diameter }(\mu \mathrm{m}) \\
\text { Mean } \pm \text { S.D. }\end{array}$ & $\begin{array}{c}\mathrm{p} \text { value Nx v/s HH } \\
\text { C or HH K }\end{array}$ \\
\hline G1 Nx & $183.29 \pm 7.79$ & - \\
G1 HH C & $177.18 \pm 13.23$ & $>0.05$ \\
G1 HH K & $167.41 \pm 6.74$ & $<0.05^{*}$ \\
G2 HH C & $181.77 \pm 3.72$ & $>0.05$ \\
G2 HH K & $170.52 \pm 7.73$ & $>0.05$ \\
G3 HH C & $161.07 \pm 2.84$ & $<0.01^{* *}$ \\
G3 HH K & $170.94 \pm 14.70$ & $>0.05$ \\
G4 Nx & $232.01 \pm 5.84$ & - \\
G4 HH C & $185.55 \pm 2.46$ & $<0.05^{*}$ \\
G4 HH K & $183.81 \pm 6.14$ & $<0.01^{* *}$ \\
G8 Nx & $166.58 \pm 9.50$ & - \\
G8 HH C & $178.80 \pm 2.90$ & $>0.05$ \\
G8 HH K & $179.39 \pm 18.36$ & $<0.05^{*}$ \\
\hline
\end{tabular}

statistically significant differences. Groups subjected to hypoxia with or without ketoprofen, G2 HH C presented significant statistical differences compared to G2 HH K, this being lower (Table IV).

Table IV. Effect of hypobaric hypoxia continuous and ketoprofen on lumen diameter of seminiferous tubules.

\begin{tabular}{lcc}
\hline Groups & $\begin{array}{c}\text { Lumen diameter }(\mu \mathrm{m}) \\
\text { Mean } \pm \text { S.D. }\end{array}$ & $\begin{array}{c}\mathrm{p} \text { value Nx v/s } \\
\text { HH C or HH K }\end{array}$ \\
\hline G1 Nx & $61.67 \pm 3.40$ & - \\
G1 HH C & $65.18 \pm 5.95$ & $>0.05$ \\
G1 HH K & $63.01 \pm 2.99$ & $>0.05$ \\
G2 HH C & $87.41 \pm 1.47$ & $<0.01 * *$ \\
G2 HH K & $62.41 \pm 3.14$ & $>0.05$ \\
G3 HH C & $64.38 \pm 2.56$ & $<0.01 * *$ \\
G3 HH K & $69.19 \pm 9.52$ & $>0.05$ \\
G4 Nx & $107.91 \pm 6.91$ & - \\
G4 HH C & $71.97 \pm 3.77$ & $>0.05$ \\
G4 HH K & $61.80 \pm 6.11$ & $<0.001 * * *$ \\
G8 Nx & $67.12 \pm 4.50$ & - \\
G8 HH C & $66.52 \pm 4.37$ & $>0.05$ \\
G8 HH K & $68.02 \pm 7.19$ & $>0.05$ \\
\hline
\end{tabular}

Height of the seminiferous epithelium. The height of the seminiferous epithelium groups evaluated as shown in Table V. Decrease is observed in epithelial height the first 33.2 days of exposure to hypoxia, showing significant statistical differences $(\mathrm{p}<0.01)$ between G1 and G2 HH C NX; G3 and G4 HH C compared with G4 Nx. At 66.4 days the height of the epithelium of the G8 group Nx groups is smaller than in hypoxia, showing very significant statistical differences between G8 and G8 HH Nx C. There are no statistically significant differences between groups subjected to hypoxia with and without ketoprofen.
Table V. Effect of hypobaric hypoxia continuous and ketoprofen on epithelium height of seminiferous tubules.

\begin{tabular}{lcc}
\hline Groups & $\begin{array}{c}\text { Lumen diameter }(\mu \mathrm{m}) \\
\text { Mean } \pm \text { S.D. }\end{array}$ & $\begin{array}{c}\mathrm{p} \text { value Nx v/s } \\
\text { HH C or HH K }\end{array}$ \\
\hline G1 Nx & $61.67 \pm 3.40$ & - \\
G1 HH C & $65.18 \pm 5.95$ & $>0.05$ \\
G1 HH & $63.01 \pm 2.99$ & $>0.05$ \\
G2 HH C & $87.41 \pm 1.47$ & $<0.01^{* *}$ \\
G2 HH & $62.41 \pm 3.14$ & $>0.05$ \\
G3 HH C & $64.38 \pm 2.56$ & $<0.01^{* *}$ \\
G3 HH & $69.19 \pm 9.52$ & $>0.05$ \\
G4 Nx & $107.91 \pm 6.91$ & - \\
G4 HH C & $71.97 \pm 3.77$ & $>0.05$ \\
G4 HH & $61.80 \pm 6.11$ & $<0.001^{* * *}$ \\
G8 Nx & $67.12 \pm 4.50$ & - \\
G8 HH C & $66.52 \pm 4.37$ & $>0.05$ \\
G8 HH & $68.02 \pm 7.19$ & $>0.05$ \\
\hline
\end{tabular}

\section{DISCUSSION}

The percentage of hematocrit in the groups of animals subjected to hypoxia significantly increased relative to control mice, especially the 33.2 and 66.4 days. This agree with what was postulated by Guyton \& Hall (1996) indicating that although these increases, in human, may be slow, manifesting after two weeks have passed and only carried out completely after many months. This increase in hematocrit which reflects the physiological response is triggered against the decrease in concentration of oxygen available in hypoxia. The body responds to this condition compared accelerating erythrocyte production by increasing the delivery of oxygen to tissues, offsetting the decline in circulating oxygen (Siques et al., 2014). Ketoprofen administration did not modify this response, with similar percentages of animals without administration of ketoprofen (de Souza Silva et al., 2006).

These results agree with previous studies by BustosObregon \& Celis (1982) who observed an increase in red cell mass as an adaptive mechanism to hypoxic environment in mammals. Another experiment conducted in rats exposed to continuous hypobaric hypoxia and intermittent hypobaric hypoxia (with cycles of intermittent hypoxia and 4 days on 4 days in normoxia for 12 days) in hypobaric chamber simulating $4100 \mathrm{~m}$, reported a significant increase in red cell mass in animals subjected to hypoxia (Farias et al., 2005).

The observed results are consistent with the bibliographic information gathered, that said the increase in erythrocytes is the result of slowly adapting response to low oxygen levels in the body that triggers the increase of the 
hormone erythropoietin by the kidney. As the reticulocyte count, the results show a significant increase in animals subjected to hypoxia relative to controls, who maintained baseline reticulocyte. Unlike the hematocrit, percent reticulocytes diminished at the end of the second month of exposure to hypoxia (Núñez-Espinosa et al., 2014; Viscor et al.). The administration of ketoprofen in animals did not change this condition, remaining increased the percentage of reticulocytes. These results together with the results of the hematocrit described above, reflect the response of the body against hypoxia produced since erythrocyte production acceleration increases the presence of these immature blood formed elements (Chignell \& Sik, 1995).

Regarding the morphometry of seminiferous tubules, the tubular diameter in the groups subjected to hypoxia presented a significant decrease to 33.2 days. The height of the epithelium, the first presented decreased 33.2 days in the group without administration of ketoprofen. Hypoxia would be an impact on the proliferation of spermatogonia found in active mitotic process which generates structural disruptions that affect the entire spermatogenic machinery. This alteration in the tubules coincides with studies Farias et al., (2005) and Bustos-Obregón et al. (2006), who reported a decrease in tubular diameter and height of the seminiferous epithelium in rats subjected to hypoxia. They postulate that the decrease in the proliferation of stem cells is due to the restriction imposed metabolic hypoxia. Also attributed the decrease in tubular diameter at reducing angiogenesis testicular interstitial space adjacent to the seminiferous tubules. The administration of ketoprofen have a protective effect on the height of the epithelium.

Histopathological examination of the seminiferous tubules showed a significant increase in the histopathological alterations to 33.2 and 66.4 days in the hypoxic group without ketoprofen; and a significant increase to 66.4 days in the hypoxic group with ketoprofen. Tubular atrophy was observed only in these three groups, buffering tubulas observed in the groups subjected to hypoxia and vacualization in all groups greater or lesser percentage. The increased production of EROS affects the structural organization of the tubular epithelium which would be related to the decreased proliferation aforementioned germ cells (Iqbal et al., 2019). Ketoprofen have a protective effect and a tendency to decrease the percentage of alterations to 33.2 and 66.4 days shows, but this effect is not statistically significant.

CONCLUSION. In conclusion, exposure to hypobaric hypoxia alters reproductive physiology decreasing the tube diameter, this decrease is maintained at the end of 66.4 days; no decrease in epithelial height the first 33.2 days, then increase the height of the epithelium at the end of 66.4 days was higher than in the normoxic group was 66.4 days; there is an increase in pathological changes to 33.2 days and 66.4 percentage changes greater. Concerning the haematological parameters, hematocrit increases and remains high hypoxia 66.4 days, the higher the percentage of reticulocytes only the first 33.2 days, then reached normal at the end of the 66.4 days levels. Accordingly, we can not say that there is complete adaptation to continuous hypobaric hypoxia, less so within the first 66.4 days (two full spermatogenesis) as the only variables that were recovered and the height of the epithelium decreased. Regarding hypoxic ketoprofen treated groups, decrease in angiogenesis, therefore presents a degree of protection to testicular level.

ACKNOWLEDGMENTS. Dedicated to the memory of Dr. Eduardo Bustos-Obregón.

HARTLEY, R.; CONEI, D.; TORRES, L. \& ROJAS, M. Efecto del ketoprofeno en la espermatogénesis de ratones expuestos a hipoxia hipobárica continua. Int. J. Morphol., 37(4):1572-1577, 2019.

RESUMEN: La hipoxia hipobárica $(\mathrm{HH})$ puede provocar alteraciones a nivel testicular, con aumento de la temperatura, alteración intraescrotal y deterioro de la espermatogénesis. Los antiinflamatorios no esteroidales (AINEs) como el ketoprofeno tienen propiedades antiangiogénicas, pudiendo disminuir las alteraciones testiculares. El objetivo de estudio fue evaluar el efecto del ketoprofeno en la espermatogénesis de ratones expuestos a hipoxia hipobárica continua. Se utilizaron 78 ratones macho Mus musculus $\mathrm{CF}-1$ de 3 a 4 meses de edad y se sometieron a HH en cámara a $4200 \mathrm{~m}$. Se dividieron en 13 grupos $(\mathrm{G})$ de 6 animales: 10 con ciclos de $\mathrm{HH}(1,2,3,4$ y 8, con duración de 8,3 días cada ciclo, dos grupos cada uno) y 3 en normoxia $(\mathrm{Nx})$. Se administró ketoprofeno intraperitoneal 25 $\mathrm{mg} / \mathrm{kg}$ cada 4 días. La eutanasia de estos animales se realizó al final de cada ciclo y en el caso los grupos $\mathrm{Nx}$ al final de los ciclos 1,4 y 8 . Se midió porcentaje de microhematocrito y reticulocitos en frotis de sangre y se hizo un análisis morfométrico e histopatológico de la altura del epitelio, el diámetro tubular y el diámetro de la luz tubular. Se evidenció que el hematocrito aumenta de manera continua hasta los 8 ciclos, en cambio los reticulocitos aumentan hasta los 3 ciclos. La HH continua disminuye el diámetro tubular de forma sostenida y proporcional a los ciclos de $\mathrm{HH}$, y la altura aumentó sólo en los grupos sometidos a 8 ciclos. Los grupos tratados con ketoprofeno se vio una disminución de la angiogénesis, presentando algún grado de protección a nivel testicular.

PALABRAS CLAVE: Ketoprofeno; Hipoxia hipobárica continua; Alteraciones testiculares; Angiogénesis. 


\section{REFERENCES}

Bustos-Obregón, E. \& Celis, R. Efecto de la Hipoxia en la Reproducción de Mamíferos. Función Testicular Postexposición en Cámara Hipobárica. En el Hombre y los Ecosistemas de Montaña (MAB-6). Montevideo, UNESCO-ROSTLAC, 1982. pp.37-64.

Bustos-Obregón, E.; Esveile, C.; Contreras, J.; Maurer, I. \& Sarabia, L. Effects of chronic simulated hypobaric hypoxia on mouse spermatogenesis. Int. J. Morphol., 24(3):481-8, 2006.

Chignell, C. F. \& Sik, R. H. Magnetic field effects on the photohemolysis of human erythrocytes by ketoprofen and protoporphyrin IX. Photochem. Photobiol., 62(1):205-7, 1995.

Cikutovic, M.; Fuentes, N. \& Bustos-Obregón, E. Effect of intermittent hypoxia on the reproduction of rats exposed to high altitude in the Chilean Altiplano. High Alt. Med. Biol., 10(4):357-63, 2009.

de Souza Silva, M.; Castiglia, Y. M.; Vianna, P. T.; Viero, R. M.; Braz, J. R. \& Cassetari, M. L. Rat model of depending prostaglandin renal state: effect of ketoprofen. Ren. Fail., 28(1):77-84, 2006.

Farias, J. G.; Bustos-Obregón, E. \& Reyes, J. G. Increase in testicular temperature and vascularization induced by hypobaric hypoxia in rats. $J$. Androl., 26(6):693-7, 2005.

Farias, J. G.; Zepeda, A.; Castillo, R.; Figueroa, E.; Ademoyero, O. T. \& Pulgar, V. M. Chronic hypobaric hypoxia diminishes the expression of base excision repair OGG1 enzymes in spermatozoa. Andrologia, 50(2), 2018.

Fouillot, J. \& Barrault, D. Fisiopatología y altitud. Rev. Trib. Med., 8:9-17, 1982.

Guyton, A. \& Hall, J. Fisiología de la Aviación, las Grandes Alturas y el Espacio. In: Guyton, A. \& Hall, J. Tratado de Fisiología Médica. 9th ed. Madrid, McGraw-Hill, 1996. pp.591-8.

Hralová, M.; Angerová, Y.; Gueye, T.; Bortelová, J.; Svestková, O.; Zima, T. \& Lippertová-Grünerová, M. Long-term results of enriched environment and erythropoietin after hypobaric hypoxia in rats. Physiol. Res., 62(4):463-70, 2013.

Iqbal, S.; Hameed, U.; Hasan, B.; Zia-Ul-Islam; Ahmed, M. \& Brohi, A. H. Protective potential of Vitamin E against methylphenidate-induced male gonadal changes in albino rats. Int. J. Health Sci. (Qassim), 13(3):19-23, 2019.

Irarrázaval, S.; Allard, C.; Campodónico, J.; Pérez, D.; Strobel, P.; Vásquez, L.; Urquiaga, I.; Echeverría, G. \& Leighton, F. Oxidative stress in acute hypobaric hypoxia. High Alt. Med. Biol., 18(2):128-34, 2017.

Kim, J. H. \& Han, S. S. Studies on hypoxia V. Effects of anoxia on developing connective tissue cells in rats. Anat. Rec., 165(4):531-41, 1969.

Núñez-Espinosa, C.; Douziech, A.; Ríos-Kristjánsson, J. G.; Rizo, D.; Torrella, J. R.; Pagès, T. \& Viscor, G. Effect of intermittent hypoxia and exercise on blood rheology and oxygen transport in trained rats. Respir. Physiol. Neurobiol., 192:112-7, 2014.

Okumura, A.; Fuse, H.; Kawauchi, Y.; Mizuno, I. \& Akashi, T. Changes in male reproductive function after high altitude mountaineering. High Alt. Med. Biol., 4(3):349-53, 2003.

Siques, P.; Brito, J.; Naveas, N.; Pulido, R.; De la Cruz, J. J.; Mamani, M. \& León-Velarde, F. Plasma and liver lipid profiles in rats exposed to chronic hypobaric hypoxia: changes in metabolic pathways. High Alt. Med. Biol., 15(3):388-95, 2014

Viscor, G.; Torrella, J. R.; Corral, L.; Ricart, A.; Javierre, C.; Pages, T. \& Ventura, J. L. Physiological and biological responses to short-term intermittent hypobaric hypoxia exposure: from sports and mountain medicine to new biomedical applications. Front. Physiol., 9:814, 2018.

Yao, C.; Li, G.; Qian, Y.; Cai, M.; Yin, H.; Xiao, L.; Tang, W.; Guo, F. \& Shi, B. Protection of pentoxifylline against testis injury induced by intermittent hypobaric hypoxia. Oxid. Med. Cell. Longev., 2016:3406802, 2016.

Zepeda, A. B.; Figueroa, C. A.; Calaf, G. M. \& Farías, J. G. Male reproductive system and antioxidants in oxidative stress induced by hypobaric hypoxia. Andrologia, 46(1):1-8, 2014.

\author{
Corresponding author: \\ Dra. Mariana Rojas R. \\ Laboratorio de Embriología Comparada \\ Programa de Anatomía y Biología del Desarrollo \\ Facultad de Medicina, ICBM \\ Universidad de Chile \\ Santiago \\ CHILE
}

\section{Email: dramrojas@hotmail.com mrojasr@u.uchile.cl}

Received : 15-05-2019

Accepted : 18-07-2019 